\title{
In memory of Daniel H. Teitelbaum
}

\author{
Arnold G. Coran ${ }^{1}$
}

Published online: 14 September 2016

(C) Springer-Verlag Berlin Heidelberg 2016

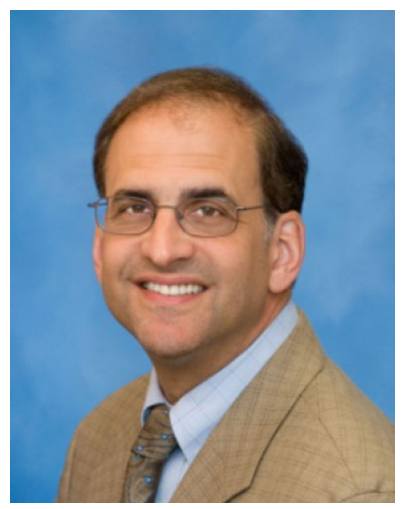

The international pediatric surgery community has suffered a major loss with the passing of Daniel H. Teitelbaum, MD, on August 17, 2016, after a long struggle with a malignant brain tumor (glioblastoma) shortly after delivering one of the major lectures at the European Pediatric Surgery Association annual meeting in Ljubljana. The loss was especially painful to us in the section of pediatric surgery in the C.S. Mott Children's Hospital at the University of Michigan Medical Center.

Dan completed his undergraduate studies at Northwestern University and earned his medical degree at Ohio State College of Medicine in 1983. After training in

Arnold G. Coran

acoran@med.umich.edu

1 C.S. Mott Children's Hospital, Pediatric Surgery-Room 4-972, 1540 East Hospital Drive, SPC 4211, Ann Arbor, Michigan 48109-4211, USA

general surgery at Ohio State University Hospital and in pediatric surgery at Columbus Children's Hospital, he was recruited to the C.S. Mott Children's Hospital as an assistant professor of pediatric surgery in 1992. Thus, began an impressive career in academic pediatric surgery, culminating in a promotion to full professor in 2004 . During this period, it was my privilege to work closely with him on clinical and basic science projects, allowing me to observe and appreciate his intellect, his humility, his commitment to his patients and his co-workers, and, above all, his devotion to his family, his wife, Mindy, and his three daughters, Hannah, Abigail and Rachel. During these last 24 years, he and I became not just close associates, but close personal friends.

Dan was involved in a wide range of general pediatric surgery disorders such as sexual development, short bowel syndrome, Hirschsprung Disease, inflammatory bowel disease and hyper-alimentation-associated liver disease. His investigative work focused on short bowel syndrome. He was recently studying ways to grow intestine using mechanical and immunological techniques. Dan published 259 peer-reviewed publications and was continuously funded by the National Institutes of Health for 17 years. He served as the President of the American Society of Parenteral and Enteral Nutrition.

In recent years, Dan assumed the position of pediatric surgery training program director at C.S. Mott Children's Hospital. His passion for teaching was exemplified in this role. In recognition of his teaching and mentoring skills, he was nominated by the former pediatric surgery residents of C.S. Mott Children's Hospital to be the recipient of the annual Section of Surgery American Academy of Pediatrics Salzberg Award, 2016. This will be presented posthumously in San Francisco at the annual meeting this coming October. Finally, in his honor, former pediatric 
surgery residents and pediatric surgery faculty of the C.S. Mott Children's Hospital, along with a family grateful for their care, established the Daniel H. Teitelbaum Collegiate
Professorship which will forever memorialize the legacy of Dan Teitelbaum within the University of Michigan Medical Center and the C.S. Mott Children's Hospital. 